\title{
EDUKASI DAN LITERASI PRODUK BANK SYARIAH BAGI SANTRI PONDOK PESANTREN AL KAUTSAR PEKANBARU
}

\author{
Mohd. Ario Wahdi Elsye*, Wahyi Busyro, Rika Septianingsih, \\ Muhammad Syahrullah Umar \\ Program Studi Perbankan Syariah, Fakultas Studi Islam \\ Universitas Muhammadiyah Riau \\ email: ariowahdi@umri.ac.id
}

\begin{abstract}
Muhammadiyah University of Riau is one of universities in Riau and every college must do catur dharma which is the vision of all universities in Indonesia. One of the forms of 'catur dharma college' is to carry out community service. Community service is an activity of academic community that utilizes science and technology to advance people's prosperity and educate the life of the nation. The form of community service undertaken by Sharia Banking Lecturers is holding a seminar with the theme "Education and Literation of Sharia Bank Product For Student of Pondok Pesantren Al-Kautsar Pekanbaru". After the holding of this seminar is expected students understand Islamic bank products and can utilize Islamic bank products well.
\end{abstract}

Keywords: Education, Literacy, Product, Islamic Bank.

\begin{abstract}
Abstrak
Setiap perguruan tinggi memiliki tri dharma yang harus dijalankan oleh dosennya. Universitas Muhammadiyah Riau tidak hanya mempunyai tri dharma namun juga catur dharma perguruan tinggi. Salah satu bentuk catur dharma perguruan tinggi adalah melaksanakan pengabdian kepada masyarakat. Pengabdian kepada masyarakat ini dilakukan agar pada dosen memanfaatkan ilmu pengetahuan dan teknologi untuk memajukan kesejahteraan masyarakat. Adapun bentuk pengabdian masyarakat yang dilakukan oleh Dosen Perbankan syariah adalah mengadakan seminar edukasi dengan tema "Edukasi dan Literasi Produk Bank Syariah bagi Santri Pondok Pesantren Al-Kautsar Pekanbaru”.'Setelah di adakan seminar ini diharapkan santri bisa mengetahui, faham dan memanfaatkan produk bank syariah dengan baik dan sesuai dengan kebutuhannya.
\end{abstract}

Kata kunci: Edukasi, Literasi, Produk, Bank Syariah

\section{PENDAHULUAN}

Edukasi dan literasi produk bank syariah keuangan merupakan hal yang sangat penting dipahami dan dimiliki oleh seluruh lapisan masyarakat pada zaman modern ini. Saat ini seluruh aktivitas tidak bisa terlepas dari perbankan dan teknologi, baik dari segi ekonomi, pendidikan dan lainnya. Di sekitar kita banyak bermunculan bankbank konvensional dengan banyak nya iklan dan penawaran produk perbankan nya, baik itu produk dalam penghimpunan dana, pembiayaan maupun produk jasa lainnya yang dimiliki oleh perbankan pada umumnya.

Di dalam perbankan saat ini sudah ada perbankan yang menjalankan operasional dan bisnis nya yang sesuai dengan Syariat Islam yaitu Bank Syariah.

Untuk menangani hal ini diperlukan kemampuan mengelola keuangan pribadi agar terhindar dari 
kemubaziran dan boros. Allah SWT berfirman dalam surat A-Isra yang artinya:"Dan janganlah kamu menghambur-hamburkan hartamu secara boros. Sesungguhnya pemboros itu adalah saudara syaithan."

Edukasi dan literasi produk bank suyariah bisa dilakukan pada setiap lapisan masyarakat, mulai dari TK, SD, SMP, SMA, PT, hingga Ibu Rumah Tangga dan lainnya. Jika edukasi ini sudah dilakukan sejak dini harapannya adalah bisa memilih dan memanfaatkan produk bank syariah dengan baik.

Indeks literasi keuangan yang disurvey oleh Otoritas Jasa Keuangan pada tahun 2016 adalah 29,66\% dan indeks inklusi keuangan sebesar 67,82\%. Menurut bank dunia, indonesia adalah negara ketiga yang mempunyai tingkat literasi keuangan paling lemah setelah india dan china. Oleh karena itu, OJK menerbitkan buku literasi keuangan bagi siswa-siswi sekolah dan melakukan seminar, pelatihan tentang literasi keuangan. Beberapa tahun terakhir ini sedang berkembang lembaga keuangan syariah, untuk membumikan lembaga keuangan syariah di indonesia diharapkan lembaga keuangan syariah dan pihak terkait bisa mensosialisasikan LKS tersebut kepada siswa-siswi sejak dini karena mereka lah yang menjadi pejuang LKS dimasa yang akan datang.

Pengabdian masyarakat bertujuan membangun pemahaman edukasi dan literasi produk bank syariah bagi santri Pondok Pesantren Al-Kautsar Pekanbaru dengan judul "Edukasi dan Literasi Produk Bank Syariah Bagi Santri Pondok Pesantren Al-Kautsar Pekanbaru". Diharapkan dengan dilaksanakannya pengabdian masyarakat ini, para santri Pondok Pesantren Al Kautsar Pekanbaru bisa memahami bank syariah dan memahami produk-produk yang ada di bank syariah.

\section{METODE PENGABDIAN}

Kegiatan ini tidak terlepas dari dukungan pihak terkait yang mendukung kelancaran pelaksanaan kegiatan pengabdian ini. Pelaksanaan pengabdian ini dimulai oleh tim pengabdian melakukan survey awal ke lokasi tempat pengabdian akan berlangsung dan berkoordinasi dengan Pimpinan Pondok Pesantren Al-Kautsar Pekanbaru untuk menetapkan waktu pelaksanaan.

Kegiatan pengabdian pada masyarakat di laksanakan dengan metode ceramah dan tanya jawab yang dilaksanakan selama 1 hari. Adapun tahapan-tahapan dalam pelaksanaan kegiatannya adalah sebagai berikut: Ceramah

Pengetahuan edukasi dan literasi bank syariah ini ditujukan untuk memberikan pemahaman kepada santri Pondok Pesantren Al-Kautsar Pekanbaru dan produk-produk bank syariah yang ada di bank syariah. Evaluasi hasil seminar dilakukan selama proses dan setelah kegiatan seminar dilaksanakan.

Pengertian bank syariah atau bank Islam dalam bukunya Edy Wibowo adalah bank yang beroperasi sesuai dengan prinsip-prinsip syariah Islam. Bank ini tata cara beroperasinya mengacu kepada ketentuan-ketentuan al-Quran dan hadits.

Bank yang beroperasi sesuai dengan prinsip-prinsip syariah Islam maksudnya adalah bank yang dalam beroperasinya itu mengikuti ketentuanketentuan syariah Islam, khususnya yang menyangkut tata cara bermuamalah secara Islam. Dalam tata cara bermuamalat itu dijauhi praktikpraktik yang dikhawatirkan mengandung unsur-unsur riba, untuk 
diisi dengan kegiatan-kegiatan investasi atas dasar bagi hasil dan pembiayaan perdagangan atau praktik-praktik usaha yang dilakukan di zaman Rasulullah atau bentuk-bentuk usaha yang telah ada sebelumnya, tetapi tidak dilarang oleh beliau.

Menurut undang-undang No. 21 tahun 2008, bank syariah adalah bank yang menjalankan kegiatan usahanya berdasarkan prinsip syariah dan menurut jenisnya terdiri atas Bank Umum Syariah dan Bank Pembiayaan Rakyat Syariah.

Secara garis besar, produk yang ditawarkan oleh perbankan syariah terbagi menjadi tiga bagian besar, yaitu produk penghimpunan dana (funding), produk penyaluran dana (financing), dan produk jasa (service).

a.Produk Penghimpunan Dana (funding)

1) Tabungan

Menurut Undang-Undang

Perbankan Syariah Nomor 21 tahun 2008, tabungan adalah simpanan berdasarkan akad wadi"ah atau investasi dana berdasarkan mudharabah atau akad lain yang tidak bertentangan dengan prinsip syariah yang penarikannya dapat dilakukan menurut syarat dan ketentuan tertentu yang disepakati, tetapi tidak dapat ditarik dengan cek, bilyet giro atau yang dipersamakan dengan itu. Tabungan adalah bentuk simpanan nasabah yang bersifat likuid. Artinya, produk ini dapat diambil bagi hasil yang ditawarkan kepada nasabah penabung kecil.

2) Deposito

Deposito menurut UU Perbankan Syariah No. 21 tahun 2008 adalah investasi dana berdasarkan akad mudharabah atau akad lain yang tidak bertentangan dengan prinsip syariah, yang penarikannya hanyadapat dilakukan pada waktu tertentu berdasarkan akad antara nasabah penyimpan dan bank syariah dan/ atau Unit Usaha Syariah (UUS).

Deposito adalah bentuk simpanan nasabah yang mempunyai jumlah minimal tertentu, jangka waktu tertentu, dan bagi hasilnya lebih tinggi daripada tabungan.

3) Giro

Giro menurut undang-undang perbankan syariah nomor 21 tahun 2008 adalah simpanan berdasarkan akad wadi" $a h$ atau akad lain yang tidak bertentangan dengan prinsip syariah yang penarikannya dapat dilakukan setiap saat dengan menggunakan cek, bilyet giro, sarana perintah pembayaran lainnya, atau dengan perintah pemindahbukuan.

Giro adalah bentuk simpanan nasabah yang tidak diberikan bagi hasil, dan pengambilan dana menggunakan cek, biasanya digunakan oleh perusahaan atau yayasan dan atau bentuk badan hukum lainnya dalam proses keuangan mereka. Dalam giro meskipun tidak memberikan bagi hasil, pihak bank berhak memberikan bonus kepada nasabah yang besarannya tidak ditentukan di awal, bergantung pada kebaikan pihak bank.

b.Produk Penyaluran Dana/

Pembiayaan (financing)

Pembiayaan atau financing adalah pendanaan yang diberikan oleh suatu pihak kepada pihak lain untuk mendukung investasi yang telah direncanakan, baik dilakukan sendiri maupun lembaga. Dengan kata lain, pembiayaan adalah pendanaan yang dikeluarkan untuk mendukung investasi yang telah direncanakan.

c.Produk Jasa (Service)

Selain menjalankan fungsinya sebagai intermediaries (penghubung) antara pihak yang kelebihan dana dan pihak yang kekurangan dana, bank syariah dapat pula melakukan berbagai 
pelayanan jasa perbankan kepada nasabah dengan mendapat imbalan berupa sewa atau keuntungan.

\section{HASIL DAN PEMBAHASAN}

Kegiatan pengabdian kepada masyarakat ini dilaksanakan di Pondok Pesantren Al-Kautsar Pekanbaru Jl. Hangtuah Ujung KM. 6,5 Kelurahan Sail Kota Pekanbaru. Terlaksananya kegiatan ini sesuai dengan jadwal yang telah ditetapkan dan disepakati pihak Pondok Pesantren dengan pelaksana. Pengabdian kepada masyarakat ini dimulai dengan melakukan tahap persiapan, pada tahap ini dilakukan observasi dan permohonan izin kepada Pimpinan Pondok PEsantren AlKautsar Pekanbaru sebagai tempat pelaksanaan pengabdian ini. Selain itu pada tahap persiapan juga mencari informasi jumlah peserta dan kegiatan peserta sebelum diadakan Seminar Eduksai dan Literasi Produk Bank Syariah. Setelah waktu pelaksanaan disepakati, tim dari Dosen Program Studi Perbankan Syariah Fakultas Studi Islam menyusun jadwal pelaksanaan dan membuat kesepakan dengan pihak Pimpinan Pondok Pesantren Al-Kautsar Pekanbaru.

Adapun tujuan dari kegiatan pengabdian ini dilaksanakan dalam rangka pelaksanaan Catur Dharma Perguruan Tinggi Muhammadiyah, yang salah satunya adalah pengabdian pada masyarakat. Seminar ini ditujukan bagi santri Pondok Pesantren AlKautsar Pekanbaru, adapun bentuk seminar berupa ceramah dan Tanya jawab berkaitan dengan edukasi dan literasi produk bank syariah. Dengan adanya kegiatan seminar ini akan dapat meningkatkan edukasi dan literasi produk bank syariah, meningkatkan pemanfaatan produk bank syariah serta kemampuan dalam melakukan perencanaan keuangan menjadi lebih baik kepada santri Pondok Pesantren Al-Kautsar Pekanbaru.

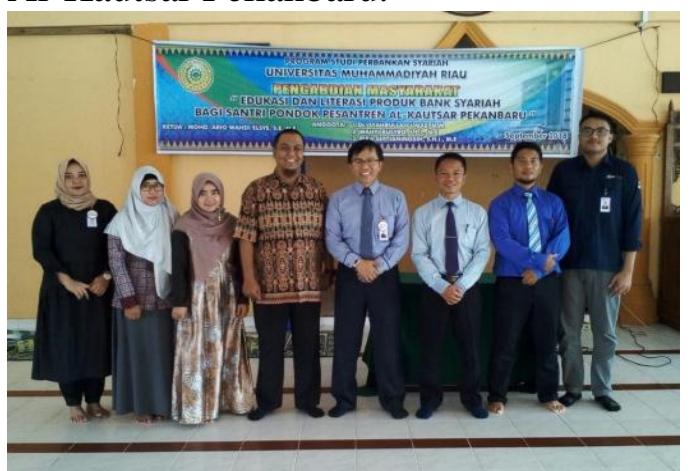

Gambar 1. Foto bersama dosen Prodi Perbankan Syariah FSI UMRI, Pimpinan Cabang BRI Syariah Pekanbaru, Pimpinan Ponpes Al-Kautsar Pekanbaru, Ustadz Pengasuh Ponpes Al-Kautsar Pekanbaru dan Karyawan/staf BRI Syariah Pekanbaru.

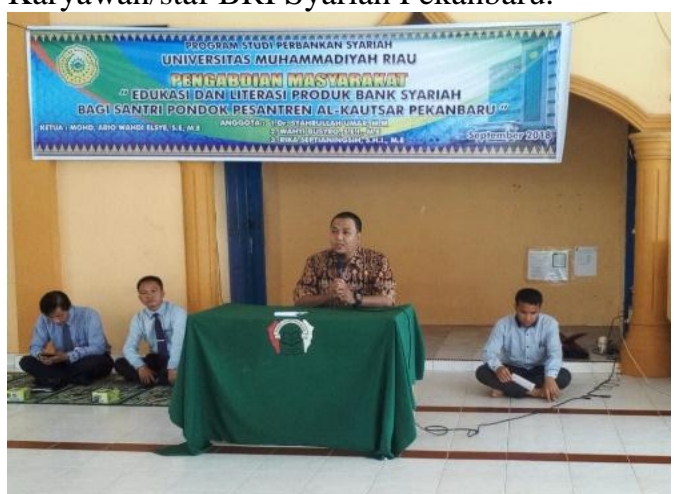

Gambar 2. Penyampaian pendahuluan dan materi edukasi produk bank syariah

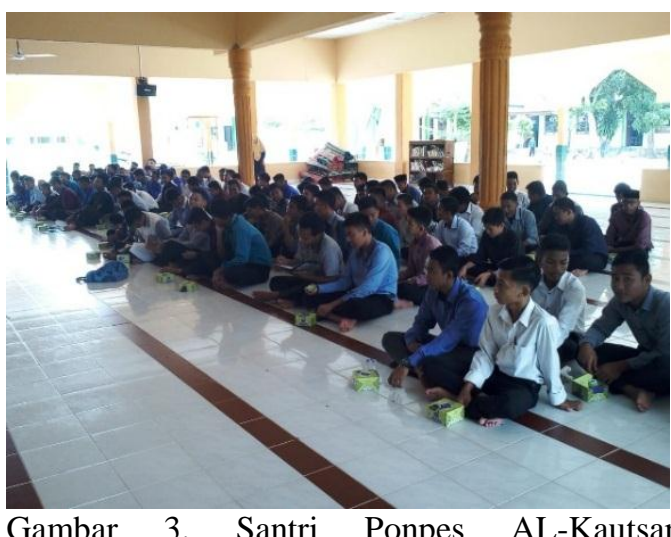
mendengarkan paparan materi edukasi produk bank syariah. 


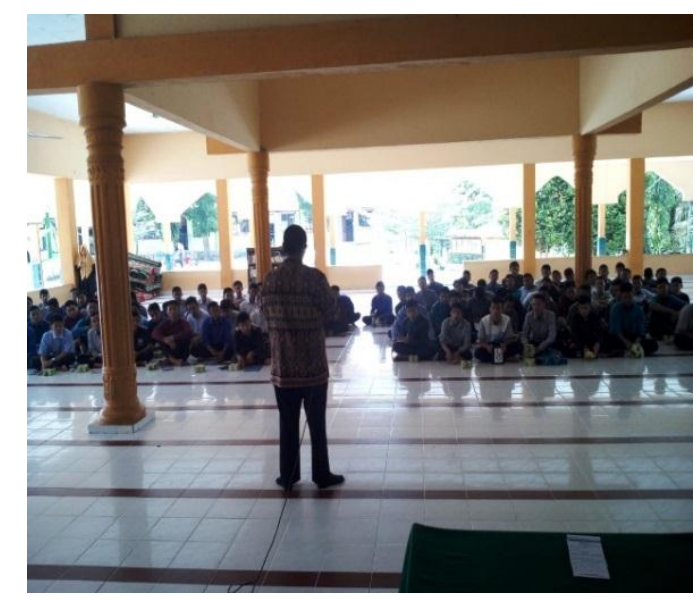

Gambar 4. Pemberian materi dan tanya-jawab edukasi produk bank syariah bagi santri Ponpes Al-Kautsar Pekanbaru

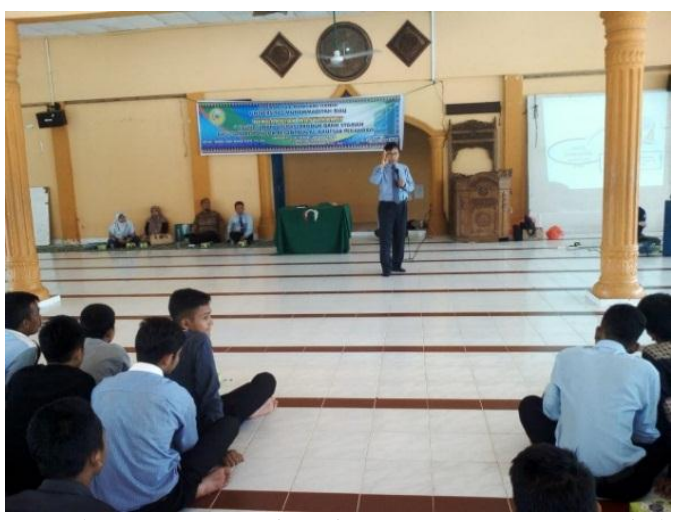

Gambar 5. Pimpinan BRI Syariah Pekanbaru memberikan materi lanjutan produk bank syariah dan manfaat dari setiap produk bank syariah

Pada tahap pelaksanaan kegiatan ini dimulai dengan tahapan persiapan, tahapan persiapan dimana tim pelaksana kegiatan melakukan konsultasi dengan angota tim lainnya, kemudian melakukan observasi terhadap santri Pondok Pesantren AlKautsar Pekanbaru dan melakukan koordinasi dengan pihak Pimpinan Pondok Pesantren Al-Kautsar Pekanbaru.

Tahapan pelaksanaan kegiatan dilaksanakan sesuai dengan waktu yang telah di sepakati pada tanggal 6 September 2018 bertempat di Mesjid Al-Kautsar Pondok Pesantren AlKautsar Pekanbaru. Tahapan pelaksanaan kegiatan dimulai dengan menjelaskan materi tentang bank syariah. Tahapan pelaksanaan selanjutnya yaitu mengenai produk bank syariah yang diisi oleh praktisi bank syariah dan kemudian dilanjutkan dengan tanya jawab mengenai edukasi dan literasi bank syariah.

Seminar edukasi dan literasi bank syariah di Pondok Pesantren Al-Kautsar Pekanbaru ini berlangsung mulai pukul $09.00-12.00 \mathrm{WIB}$.

\section{SIMPULAN}

Kegiatan seminar edukasi dan literasi produk bank syariah berjalan baik dan lancar. Seminar ini memberikan pengetahuan dan pemahaman tentang edukasi dan literasi produk bank syariah baik dari produk penghimpunan dana (funding), penyaluran dana (lending) serta jasajasa lainnya yang diberikan oleh bank syariah.

Pemahaman mengenai produk bank syariah ini harus diketahui setiap individu karena ini merupakan bekal kita dimasa yang akan datang. Diharapkan setiap sekolah mulai dari TK, SD, SMP dan SMA sudah memulai mengenalkan produk bank syariah pada tingkatnya masing-masing.

\section{UCAPAN TERIMAKASIH}

Terimakasih kami ucapkan kepada semua pihak yang mendukung kelancaran pengabdian ini terutama untuk Lembaga Penelitian dan Pengabdian Masyarakat UMRI, Pimpinan, pengajar dan santri Pondok Pesantren Al-Kautsar Pekanbaru, serta Bapak dan Ibu Dosen Fakultas Studi Islam Universitas Muhammadiyah Riau.

\section{DAFTAR PUSTAKA}

[1] Hidayat,amin. 2017. Peran OJK (Otoritas Jasa Keuangan) dalam meningkatkan Literasi Keuangan 
Pada Masyarakat terhadap Lembaga Jasa Keuangan. Skripsi.

[2] Herawati,Trisna Nyoman dan Anantawikrama. Pelatihan dasar Keuangan Untuk Meningkatkan Literasi Keuangan di Kalangan Mahasiswa. Jurnal .

[3] Riskyono, Nur Ismail. 2017. Pengaruh Pengetahuan, Religiusitas, Iklan, dan Literasi Keuangan Terhadap Minat Menabung di Bank Syariah. Skripsi.UIN Sunan Kalijaga. Yogyakarta

[4] Septiana,Aldila. Model Literasi Keuangan Pondok Pesantren Madura. Jurnal.STKIP Bengkulu

[5] Wahid, Nusron. 2014. Keuangan Inklusif : Membongkar Hegemoni Keuangan .Jakarta : Gramedia

[6] Wibowo, Edy., dkk. 2005. Mengapa Memilih Bank Syariah? Bogor: Ghalia Indonesia Cet I.

[7] M. Nur Rianto Al-Arif. Lembaga Keuangan Syariah Suatu Kajian Teoritis Praktis, Bandung : CV Pustaka Setia.

[8] Riskyono, Nur Ismail. 2017. Pengaruh Pengetahuan, Religiusitas, Iklan, dan Literasi Keuangan Terhadap Minat Menabung di Bank Syariah. Skripsi.UIN Sunan Kalijaga. Yogyakarta

[9] Otoritas Jasa Keuangan. www.OJK.go.id. Diakses pada tanggal 12 Juli 2018 